\title{
A PRODUÇÃO ESCRITA DAS MULHERES NEGRAS
}

\author{
MARIA CONCEIÇÃO LOPES FONTOURA \\ Maria Mulher - Organização de Mulheres Negras
}

\begin{abstract}
Resumo: O artigo faz uma análise dos escritos publicados por Maria Mulher - Organização de Mulheres Negras, tendo em vista atender a sua missão institucional.Inicialmente, é feita uma apresentação da forma como a organização presta informações para as mulheres, em especial, as negras, visando ao combate às discriminações sexista, de raça/etnia e de classe social dentro dos programas que desenvolve. O texto faz também referência à falta de organizações que incentivem a produção intelectual de entidades feministas negras. Finalmente, para aumentar o número de publicações das organizações de mulheres negras, o trabalho aponta para a produção de obras em conjunto, as quais abordarão temas de acordo com a vocação de cada instituição.
\end{abstract}

Palovras-chave: escritos, compartilhados, publicações, vocação, entidades.

Maria Mulher - Organização de Mulheres Negras é uma entidade feminista, cuja missão institucional é a defesa dos direitos humanos das populações marginalizadas e excluídas, principalmente, de afrodescendentes. O objetivo da organização é combater as discriminações sexista, étnico-racial e social. Criada em 8 de março de 1987, em Porto Alegre, a organização faz parte dos movimentos sociais negro, feminista e popular, inserindo na pauta de lutas destes movimentos os recortes de gênero e raça/etnia.

A partir dos anos setenta, o movimento social negro cresce no Brasil, embalado pela independência de antigas colônias européias na África, pela luta por direitos humanos dos negros nos Estados Unidos e pelo surgimento do movimento "black is beautiful", entre outros. No Brasil, surgem grupos formados por negras e negros, cujo objetivo maior é resgatar a verdadeira história da população negra no país. No início, a maioria das mulheres negras tem um papel secundário no movimento. Participam da estruturação de grupos, realizam tarefas para sua manutenção e executam atividades de enfrentamento ao racismo. Apesar de todo o trabalho que faziam, não Ihes cabia o papel da representação política nos eventos. O caráter machista da sociedade, presente no movimento social negro, Ihes reservava a atribuição de representar aos homens negros.

Maria Mulher surge da necessidade de as mulheres negras ocuparem seu papel protagônico na luta contra o racismo, o sexismo e a exclusão social. A entidade, no início, realizou intervenções, chamando a atenção para a história da luta das mulheres negras na sociedade brasileira. Alerta para a necessidade do movimento social negro respeitar, valorizar e estimular a participação das mulheres negras.

O protagonismo das mulheres negras era desconsiderado pelo movimento feminista emergente no país. A fala de suas lideranças referia-se à situação específica das mulheres 
não-negras. Reforçava-se também, a importância da mulher trabalhar fora, de estudar para conquistar autonomia econômica e respeito dos maridos e companheiros. Esta retórica esquecia que as mulheres negras eram trabalhadoras, por excelência. A família tinha um outro formato para as mulheres negras. Ao passo que a família não-negra era triangular, composta do pai no vértice do triângulo, da mãe e dos filhos na sua base, a família de origem africana era circular, acolhendo parentes consangüíneos e pessoas sem parentesco real. Neste núcleo, as mulheres, muitas vezes, constituíam a base de sustentação econômica. Em muitos casos, a figura do pai mantenedor, estava ausente. Uma das perversidades do pós-escravidão foi jogar o homem negro na marginalização sócio-econômica. Ele passa a fazer parte do exército de reserva no mundo do trabalho. O país importa europeus para executar o papel de trabalhador livre.

As publicações de Maria Mulher assumem as bandeiras específicas das mulheres negras brasileiras. As organizações negras, em sua maioria, apresentam uma produção teórica ainda muito incipiente. Para evitar juízos preconceituosos e discriminadores, reforçando o processo de exclusão de afro-brasileiros, é preciso conhecer a história brasileira. Os cento e quinze anos que distam do final da escravização de africanos, africanas e seus descendentes apresentam marcas fortes do período escravista. O acesso à educação é dificultado para uma parcela da população negra brasileira. A inserção no mundo da escrita está em processo. A presença da oralidade, característica da cultura de matriz africana, é pouco valorizada no país. Há dificuldade de patrocínio para a publicação das obras produzidas pelas mulheres negras brasileiras. Milhões de mulheres negras brasileiras estão distantes das formas modernas de comunicação. Não têm acesso ao telefone convencional, celular, fax, computador, Internet, intranet... que Ihes possibilitem uma comunicação imediata com o mundo.

A dificuldade de acesso aos modernos meios de comunicação impede que as mulheres negras recebam informações. A comunicação é fundamental para aquisição de conhecimentos e estes representam poder, mesmo que simbólico. Quem sabe domina, quem não sabe é dominado. O distanciamento dos benefícios oferecidos pela comunicação faz com que milhões de mulheres negras sejam detentoras de cidadania inconclusa. Apesar de todos os entraves enfrentados, as mulheres negras brasileiras conseguem driblar os problemas e fazem circular informações importantes ao longo destes cinco séculos.

A comunicação oral é uma forma própria de circulação de informações entre a população negra brasileira. No continente africano, os griôs, pessoas detentoras de conhecimentos, percorriam diferentes regiões, transmitindo oralmente diferentes ensinamentos. De forma similar, o correio nagô faz circular informações entre o povo negro. O abrasileiramento da forma de comunicação existente na África originou o chamado correio nagô. A desterritorialização de africanas e africanos separou famílias e grupos étnicos, a fim de facilitar a dominação, porém não impediu que, na diáspora, fossem construídas formas próprias de resistência. A luta pela sobrevivência fez com que fossem vencidas as barreiras lingüísticas. Os trabalhadores escravizados da casa grande, que tinham um contato maior com os escravocratas, aos poucos passaram a dominar a língua portuguesa e transmitiam àqueles que trabalhavam na lavoura informações importantes, possibilitando a construção de formas de resistência, para buscar a liberdade.

Até o presente momento o caráter da oralidade, uma característica da cultura africana, ainda não recebeu a devida valorização da intelectualidade brasileira. Os intelectuais reforçam, sobremaneira, a cultura letrada européia. Esquecem, entretanto, que foi no continente africano que surgiu a escrita. Os hieróglifos, forma de escrever descoberta pelos egípcios, representavam a introdução da escrita no nosso mundo. Em 
Alexandria, norte da África, existiu a maior biblioteca da época. É pouco divulgado que os malês dominavam a escrita. Outros grupos étnicos detinham um conhecimento avançado sobre o uso de minerais, como o ferro. Conhecer a história da África é importante para desconstruir idéias preconceituosas e discriminadoras sobre o continente africano.

Do mesmo modo que o conhecimento significa poder, a sua ausência é sinônimo de dominação. Maria Mulher, tendo em vista universalizar as informações, apresenta escritos em sua área de atuação. O primeiro material produzido pela organização foi o Boletim n.1, publicado em novembro de 1987. A apresentação abordava o tema do centenário da Abolição da Escravatura no Brasil que aconteceria no ano seguinte. $O$ Grupo chamava a atenção para a utilização que o evento poderia ter por parte do governo do país naquele momento. Criticamente alertava para o modo como o governo abordaria o evento. A idéia era realizar uma grande festa, sem atentar para a situação em que se encontravam milhões de negras e de negros brasileiros, transcorridos cem anos do final legal da escravidão. A par da atitude governamental, vinha a postura que o movimento social negro adotaria.

O ano de 1988, de acordo com o calendário do governo Sarney, prevê os festejos do centenário da Abolição da Escravatura no Brasil. O MINC - Ministério da Cultura elaborou uma vasta programação em quase todos os estados da União, com o objetivo de fazer uma grande festa, dentro do espírito da "democracia racial" que sustenta o discurso liberal das elites dominantes do país. Só que a negrada não "está aí pra bobo". A postura adotada pelo Movimento Negro tem sido de repudiar o festão e contrapor-se com alguns eventos, sem cunho festivo, mas que propõem reflexão e análise sobre a real condição do Povo Negro, buscando soluções alternativas para os vários e diferentes problemas que atingem a comunidade negra (Boletim $\mathrm{n}$. 1, 1987).

A apresentação conclui informando que Maria Mulher estará ao lado dos setores que elaborarão uma proposta alternativa de programação para o Centenário, “... que vise simbolizar os 100 ANOS DE RESISTÊNCIA, reafirmando os valores culturais e a grande contribuição para o desenvolvimento da sociedade brasileira dada pelos negros".

O Editorial relata o início do grupo:

Reuniram-se em 8 de março deste ano, algumas mulheres negras com o objetivo de refletir, discutir e até formar um grupo que desse continuidade a uma ação política voltada à Mulher Negra. Sendo que esta ação elaborada por homens e mulheres, dispostos a por fim às relações de discriminação de gênero, de raça e de classe em nossa sociedade (Boletim n. 1, 1987).

Ressalta também que os negros foram vítimas ““... do maior genocídio da história brasileira"”. Maria Mulher faz ligação entre causa e conseqüência. A escravização de milhões de africanos e africanas e descendentes e a abolição sem proteção aos construtores e construtoras da nação. O texto afirma contundente ““... se nossos antepassados viviam em senzalas, hoje, nós continuamos vivendo nas vilas e favelas, ocupando o mais baixo estrato social, imposto pelo sistema capitalista"'.

A partir da análise feita pelas componentes do grupo na época, é estabelecida a missão do grupo naquele momento histórico.

Face a essa realidade social, econômica e cultural da população negra, o grupo compreende que deva desenvolver uma ação, um trabalho visando socializar o conhecimento, resgatando e valorizando nossa cultura e assim contribuirmos para a construção de uma sociedade justa e igualitária, garantindo o respeito às especificidades raciais e sexuais do conjunto da população.(Boletim n. 1, 1987). 
A conclusão do Editorial menciona o estágio em que o grupo se encontra, ao mesmo tempo em que aponta para propostas de atuação a serem seguidas:

Diante do estágio embrionário do Grupo, algumas propostas de trabalho estão sendo implementadas, por exemplo, estamos lançando o primeiro Boletim, que é um veículo aberto aos demais grupos e entidades do movimento negro, que partilham de nossas idéias, somando-se aos demais movimentos sociais que buscam garantir de forma organizada seus direitos (Boletim n.1, 1987).

Outras notícias de interesse da comunidade negra fizeram parte do primeiro número do Boletim de Maria Mulher. Sob o título Exigimos Justiça é relatado um ato público ocorrido no dia 30 de outubro, às 15 horas, em frente ao Supermercado DOSUL, na Avenida Bento Gonçalves, chamado pelo Movimento Negro/RS, em repúdio ao assassinato do operário Júlio Cessar de Melo Pinto por policiais militares em maio daquele ano. A coluna Sugestão recomenda a leitura do livro Mulher negra, de Sueli Carneiro e Thereza Santos'

O artigo Cabeça de Mulher ressalta as várias formas de enfrentar o racismo ou como se pode ser por ele derrotado.

Dia vinte de novembro, Dia Nacional da Consciência Negra, data que convida à reflexão. O caráter mal disfarçado do racismo brasileiro favorece uma série de atitudes na negrada Há aqueles que procuram incansavelmente afastar as marcas de sua origem negra. É cabelo alisado, é pó facial embranquecedor, é fuga aos raios do sol para não deixar a melanina trair... Há quem busque mostrar que é negro por fora, mas tem a "alma branca". Introjetou as inverdades que "rolam" a respeito do negro. "Negro é tudo que é ruim." Não questiona estas falsas afirmações. A "real" é que o negro foi o construtor deste país. Trabalhou de sol a sol, inundou com o seu sangue o solo "pátrio". Foi durante muito tempo o único trabalhador no país. Tudo era feito por mãos negras. Batalhou até a morte em cidades, fazendas e minas. Portanto, o negro é o vagabundo mais trabalhador que o país teve (Boletim n. 1, 1987).

Continuando, o artigo ressalta o caráter de protagonista desempenhado por africanos, africanas e seus descendentes durante o período escravista.

O negro não foi o escravo passivo que mostram. Lutou para ser livre e para que todos vivessem com dignidade, sem a exploração do homem pelo homem. Várias foram as lutas empreendidas. Nos quilombos, buscou construir uma vida própria. Palmares, mais de 100 anos de resistência coletiva, uma verdadeira epopéia negra. Muitos outros momentos de dignidade coletiva estão presentes na história do negro brasileiro (Boletim n. 1, 1987).

O texto também passeia pelas várias formas como os negros se colocam na sociedade. "“Existem os que se assumem e se impõem como negros. Alma negra, valores negros e atitudes negras."' Cabe, aqui, destacar o entendimento do Grupo sobre a forma de relacionamento com os não-negros. Maria Mulher ressalta que os negros que defendem o seu protagonismo "“não se preocupam em agradar aos não-negros, pois sabem que aqueles que Ihes são "solidários", os aceitam e respeitam, sem exigir um servilismo degradante."”

O texto conclui, fazendo um chamamento à população negra, para que mantenha a dignidade conquistada pelos negros e pelas negras quilombolas.

... É necessário ser o quilombola dos anos 80 , lutando pela sua valorização como pessoa. O negro deve batalhar por uma vida melhor, digna e justa para o conjunto da negrada ... A hora exige consciência e decisão ... Devemos manter a identidade negra, sem procurarmos ser apenas negro de dentes arreganhados e cabeça vazia. O velho chavão de outras lutas cabe aqui: negro unido, jamais será vencido (Boletim n. 1, 1987).

134 Estudos Feministas, Florianópolis, 12(N.E.): 131-141, setembro-dezembro/2004 
Também fez parte do primeiro Boletim de Maria Mulher, uma coluna destacando os eventos da época. Destaca-se a apresentação de um vídeo, seguido de debate, no bairro Jardim Leopoldina, proposto pelo grupo. A chamada para o evento "Jante com Maria" também proposição do Grupo. Outro comunicado é sobre as reuniões do grupo, aos domingos, na Garagem, primeira sede da organização, na Rua Mucio Teixeira. Outro evento destacado refere-se ao encontro realizado pela Pastoral do Negro. Foi avisado que o Grupo Semba estaria promovendo uma atividade cultural na Escola Julio Grau, no Passo D'Areia. Foi informado que aconteceria a $1^{a}$ reunião preparatória para o Encontro Nacional de Mulher Negra, a ser realizado em Salvador. O informe final foi sobre a realização da ll Semana do Negro, promovida pela Prefeitura Municipal de Porto Alegre em parceria com entidades do Movimento Negro, período de 14 a 20.11.87.

O Boletim abordou a temática da sexualidade, fazendo referência aos direitos humanos das negras.

A mulher negra no Brasil tem sofrido ao longo dos anos um processo de alienação de sua identidade. Enquanto escrava tentaram coisificá-la. Não era vista como pessoa, era apenas objeto de uso. No entanto a opressão constante não the tirou a dignidade. A mulher negra destacou-se nas lutas de resistência, na revolta dos malês, na Bahia: - Luiza Mahim, no Quilombo dos Palmares, em Alagoas: Acotirene, entre outras (Boletim n. 1, 1987).

O texto ainda abordou a transposição da mulher negra da senzala para a periferia das cidades; criticou a ditadura dos padrões de beleza e bradou pelo espaço das mulheres negras no movimento feminista que emergia naquele momento. "'A sociedade capitalista que emergiu, acaba com a "escravidão", tirando-a das senzalas para jogá-las nos barracos, à margem da sociedade." " O brado contra o desrespeito à mulher negra é contundente. "“Nós mulheres negras exigimos o respeito ao nosso padrão de beleza, conforme as características de nosso tipo físico, sem sermos vistas como alimento para apetites e taras sexuais doentios"'. Para o movimento feminista, composto por mulheres não-negras, em sua maioria, e desconhecedoras do protagonismo das negras, vai o recado:

... no tocante ao movimento feminista, cabe-nos frisar que enquanto as mulheres brancas lutam para conquistar o direito ao prazer, nós negras ainda estamos batalhando pela sobrevivência, responsáveis que somos, muitas vezes, pela manutenção da família. Desta maneira, fica prejudicada a organização das mulheres negras em torno de suas questões específicas, entre elas a valorização do corpo, o direito ao prazer ...(Boletim n. 1, 1987).

O Boletim apresenta ainda o tema Movimento Negro e as Eleições, chamando atenção para a eleição da Assembléia Nacional Constituinte em 1986, quando somente um parlamentar negro foi eleito, tendo em vista a sua atuação junto ao movimento sindical. O texto ressalta a necessidade de o Movimento Social Negro estabelecer “... uma política de alianças com aqueles setores progressistas, que se aliam às lutas contra a discriminação racial, contra o racismo e pela transformação da sociedade."

O combate às pretensões pessoais de candidaturas negras estão presentes no texto,

... Por outro, se faz necessário neutralizar os projetos políicos pessoais, que tem entravado o crescimento do Movimento Negro, como de resto da sociedade civil, trazendo para seu interior práticas oportunistas e equivocadas, que comprometem a unidade e a mobilização do Movimento Negro (Boletim n. 1, 1987).

Este texto conclui exaltando o importante momento histórico da luta contra o racismo, representado pela Frente Negra Brasileira “..... que provou que a unidade dos oprimidos será alcançada na luta, com a organização, na defesa de seus interesses de classe, gênero e raça"'". 
O detalhamento do primeiro Boletim de Maria Mulher deve-se à necessidade de apontar para que existe produção textual no seio dos movimentos sociais negro e de mulheres negras, dotado de características próprias, a fim de facilitar a comunicação com a sua base de militância.

Maria Mulher lançou em janeiro de 1988, seu segundo Boletim. A apresentação intitulada Heróis da Resistência chama atenção para a necessidade de a comunidade negra estar alerta para os festejos do centenário da Abolição, e também, ficar atento para os festejos do carnaval, desviando-se da violência, muito comum nesta época.

O Editorial ressalta que o país, naquele momento, estava vivendo uma grave crise econômica, por isso havia o aumento da miséria, recaindo um fardo pesado sobre a população negra. Esteve presente a crítica à má distribuição da riqueza nacional.

Qual é a causa de tudo isto? A razão desta crise está na maneira como é administrada a riqueza do país. O sistema capitalista, em vigor no Brasil, tem a sua base econômica voltada para a propriedade privada dos meios de produção, ou seja, um pequeno grupo de pessoas é dona dos grandes negócios ... enriquecendo descaradamente às custas da massa de trabalhadores (Boletim n. 2, 1988).

O texto se mantém, de forma crítica. Conclui, convocando a sociedade para participar da ““.... transformação da sociedade através de suas entidades: movimento negro, movimento sindical, movimento dos bairros, para reverter este quadro de injustiça e exploração do homem pelo homem, para alcançarmos uma sociedade justa e igualitária"”.

O Boletim n. 2, noticiou o julgamento dos militares responsáveis pela execução de Júlio César de Melo Pinto, o homem errado. Os juizes militares condenaram, após 16 horas de julgamento, os responsáveis pela acusação. "Essa vitória representa um marco dos negros contra a violência policial da qual somos vítimas constantes. Mostra aos negros e ao povo em geral que, somente organizados e unidos, poderemos avançar na luta por justiça para todos".Algum tempo depois os culpados foram a novo julgamento e inocentados pela Justiça Militar.

Desde janeiro de 2000 , a organização vem realizando suas publicações, dentro do que chama de Passaporte para a Cidadania. São escritos que buscam oferecer subsídios, visando instrumentalizar a população afrodescendente, a fim de que oportunizar instrumentos para enfrentar a discriminação racial e o racismo presente na sociedade brasileira, a fim de garantir a cidadania plena.

O primeiro livro foi feito pelo Programa SOS RACISMO - Um Serviço Essencial para a Cidadania que Maria Mulher desenvolveu em parceria com o Ministério da Justiça/ Secretaria de Justiça/Departamento de Promoção dos Direitos Humanos. A obra teve como finalidade instrumentalizar as pessoas vítimas de discriminação racial com informações necessárias, para que pudessem reagir e denunciar a discriminação sofrida. O manual constituiu-se de nove itens.

O item 1 se intitula "O que é SOS RACISMO E O QUE FAZ" e constitui-se como um rápido histórico sobre a criação do programa. Informa como acontecerá o atendimento às vítimas de discriminação. É sabido que a agressão de racismo, além do ferimento ao direito a ser respeitado, conforme a raça/etnia, atinge sobremaneira o estado psicológico e interfere nas relações interpessoais. A vítima da discriminação sofre um abalo na sua esfera emocional. A pessoa discriminadora e racista, através de ofensas, busca menosprezar o grupo de origem étnico/racial da vítima. Nos casos ocorridos nas relações de vizinhança estabelecese uma ruptura no convívio entre vizinhos, passando a haver um distanciamento entre pessoas que coabitam um espaço em comum. Muitas vezes, para evitar constrangimento entre vizinhos, os casos de discriminação racial não são levados adiante. Existe uma crença de 
que o a/o ofendida/ofendido racialmente deve ser "superior" e ignorar a ofensa. Trata-se de uma inverdade. "Não basta dormir, porque a dor não passa", ou seja, ignorar que foi vítima de discriminação étnica-racial, não elimina ou invalida a dor e a agressão recebidas. O silêncio fortalece atitudes de discriminação étnico-racial.

A obra tem a finalidade de encorajar a denúncia do ato criminoso, além de oferecer suporte de ajuda, buscando desconstruir o tratamento banal, comumente atribuído às situações de discriminação racial. A banalização dos atos discriminatórios fortalece a sua repetição. Na medida em que se busca pôr limites a estas atitudes, está-se construindo novas formas de relação na sociedade. É sabido que a mudança de comportamento é muito lenta. Considere-se, por exemplo, os ideais da Declaração de Direitos Humanos que, passados meio século, ainda estão em fase de consolidação. $\mathrm{E}$, como se não bastasse a Declaração referir-se aos direitos fundamentais dos seres humanos, foi necessário que posteriormente se afirmasse que os direitos das mulheres também são direitos humanos. $A$ eqüidade de direitos está na Constituição Federal de 1988, no título II - Dos Direitos e Garantias, no Capítulo I - Direitos e Deveres Individuais e Coletivo reza explicitamente no Art. 5 que: "Todos são iguais perante a lei, sem distinção de qualquer natureza, garantindose aos brasileiros e aos estrangeiros residentes no Pais a inviolabilidade do direito à vida, à liberdade, à igualdade, à segurança e à propriedade nos termos seguintes:

...XLI - a lei punirá qualquer discriminação atentatória dos direitos e liberdades fundamentais; XLII - a prática do racismo constitui crime inafiançável e imprescritível, sujeito à pena de reclusão, nos termos da lei..."

A igualdade legal, garantida pela Constituição não se aplica à vida diária da população afrodescendente, que continuadamente é desrespeitada em seus direitos.

Maria Mulher refere este tema no segundo item de sua Cartilha, ao tratar da Constituição Brasileira e o Direito à Igualdade.

No item 3, "PASSOS A SEREM SEGUIDOS PELO SOS RACISMO", estão elencadas uma série de iniciativas que devem ser tomadas pelas vítimas de discriminação racial. Para que o caso de discriminação tenha seguimento, faz-se necessário que a vítima denuncie o ato discriminatório. O conhecimento da forma de proceder nos casos de discriminação racial é importante para que as vítimas se encorajem e denunciem o crime sofrido, para que se possam acionar os instrumentos legais, a fim de que as pessoas criminosas sejam penalizadas conforme a lei preceitua.

No item 4, "EVITE SER CÚMPLICE DO RACISMO" estão elencadas recomendações para que as pessoas evitem reforçar as situações discriminadoras, como, por exemplo, repetir piadas racistas, utilizar palavras que liguem a cor preta a situações ruins. Evitar ser chamado por apelidos ligados à sua cor, repudiar a animalização. Há a recomendação de buscar informar-se e participar de atividades que versem sobre a valorização da população afrodescendente, assim como se propõe que as pessoas cada vez mais busquem informações a respeito da cultura de matriz africana.

$O$ item 5 refere a necessidade de "REAGIR E DENUNCIAR O RACISMO", a fim de assegurar o pleno exercício da cidadania. Combater a negação da atitude discriminatória é fundamental. Combater o descaso com o acontecido é fundamental para a luta contra a discriminação étnico/racial. A vítima de discriminação étnico-racial deve denunciar e enfrentar a situação discriminadora, buscando apoio principalmente junto a entidades que defendem os direitos humanos.

OS "PROCEDIMENTOS A SEREM REALIZADOS NOS CASOS DE DISCRIMINAÇÃO RACIAL" encontram-se relacionados no item 6 do Manual. $O$ correto registro da ocorrência é fundamental. Identificar testemunhas sempre que possível. Acompanhar a feitura da 
ocorrência, a fim de que ela registre com fidelidade o que ocorreu. Procurar as instâncias legais para a representação da denúncia. Se não puder contratar um defensor, procurar o Ministério Público que oferecerá um advogado para encaminhar o caso.

"O PAPEL DA LEGISLAÇÃO ANTIDISCRIMINATÓRIA" consta do item 7 do manual. Reporta-se às leis de $n^{\circ} 7716 / 89$, denominadas Lei CAÓ, de 5 de janeiro de 1989. Este instrumento legal tipificou os vários crimes de preconceito e de cor. Além disso, há a Lei 9459, de 13 de maio de 1997 (Lei PAIM) que alterou o Código Penal, introduzindo a chamada Injúria Racial, ou Injúria Qualificada, ““.... que consiste na utilização de elementos referentes à raça, cor, etnia, religião ou origem"”, determinando pena de reclusão de um a três anos e multa.

O título 8 - "TEXTO DAS LEIS ANTI-DISCRIMINATÓRIAS"- reproduz o texto das Leis n. 7716/ 89, de 05 de janeiro de 1989 (Lei CAÓ) e da Lei n. 9459, de 13 de maio de 1997 (Lei Paim). Também são referidas as Leis $n$. 9455, de 7 de abril de 1997 que definem os crimes de tortura e dão outras providências; a Lei n. 8069, de 13 de julho de 1990 que dispõe sobre o Estatuto da Criança e do Adolescente, e dá outras providências; a Lei n. 8079, de 11 de dezembro de 1990, que dispõe sobre a proteção do consumidor e dá outras providências; bem como indica uma série de leis que fazem parte do código penal e versam sobre antidiscriminação.

O item 9 indica "OUTRAS ENTIDADES QUE SE ENCONTRAM ENVOLVIDAS NA LUTA ANTIDISCRIMINATÓRIA". São entidades governamentais e não-governamentais relacionadas com o combate às discriminação. A obra conclui com as referências bibliográficas utilizadas para a elaboração da cartilha.

Tendo em vista que a Cartilha foi concebida anteriormente à realização da III Conferência Mundial Contra o Racismo, a Discriminação Racial, a Xenofobia e as Formas Correlatas de Intolerância, o documento não contemplou as decisões e o plano da referida Conferência. Porém, neste momento, é de vital importância assumir aquelas decisões, pois elas unificam em nível mundial o combate às práticas racistas e discriminatórias.

A importância da Cartilha reside no fato de servir para alertar e orientar as pessoas sobre a necessidade de se combater o racismo e a discriminação racial, adotando um comportamento cidadão ao reagir à "naturalidade" do racismo e da discriminação racial, formas de comportamento ainda muito comuns em nossa sociedade. Trata-se de reagir buscando o respeito às diferenças, pois ser diferente não significa ser inferior. A riqueza cultural da sociedade brasileira reside principalmente, na sua diversidade.

O segundo número do Passaporte para os Direitos Humanos, produzido por Maria Mulher se intitula Cuidar da saúde é coisa de mulher. Esta publicação tem por fim servir de instrumento de disseminação de informações, prioritariamente, a mulheres nãoalfabetizadas, vítimas de violência doméstica, portadoras de HIV, doentes de AIDS e a meninas e adolescentes em situação de risco e vulnerabilidade social.

Para oportunizar uma ampla compreensão do tema que está sendo tratado, a cartilha apresenta desenhos indicando, de forma explícita, a temática tratada, a fim de que, principalmente, as mulheres não-alfabetizadas, consigam entender a mensagem passada. Aborda as diferentes formas como se contrai o vírus da AIDS. Ao mesmo tempo aponta para a necessidade de se buscar o tratamento da doença. Indica que a realização do teste para saber se é portador do vírus ou se está doente de AIDS é gratuito e seu resultado é sigiloso.

A Cartilha desmistifica informações não verdadeiras sobre as formas de aquisição da doença. Salienta a importância do convício social para as pessoas doentes e/ou portadoras do vírus da AIDS. Apresenta as diferentes formas de proteção que devem ser adotadas pelas pessoas, a fim de proteger-se e/ou evitar a disseminação da doença. O uso de camisinhas masculina e feminina é incentivado. Alerta-se para o não-compartilhamento de seringas. É ensinado o modo correto de usar as camisinhas feminina e masculina. 
A Cartilha também trata da violência a contra a mulher, demonstrando as suas várias facetas: a violência física, social, étnico-racial, psicológica e sexual e apresenta formas de combatê-la. Encoraja as mulheres a buscarem ajuda. Indica que a Delegacia de Polícia, o Posto de Saúde e entidades que lutam pelos direitos das mulheres são espaços onde poderão receber apoio, a fim de combater a violência sofrida.

A Cartilha termina incentivando as mulheres a lutarem pela sua felicidade, desmistificando idéias de que as mulheres nasceram para padecer no paraíso. A inclusão de tipos étnico-raciais diferenciados serve para desconstruir estereotipias. A violência contra a mulher ocorre em todos os espaços, não só nos desprovidos socialmente. É sabido que nestes locais há um agravamento da violência, por conta das discriminações sexista, étnico-racial e social. As mulheres de classe social mais elevada, vítimas de violência, muitas vezes não denunciam a violência sofrida, mas recorrem a serviços de profissionais que as ajudam a reagir e enfrenta-la.

Palavras de Maria Mulher é outra publicação da entidade. A fim de publicizar os programas realizados, a entidade publicou o Boletim da Organização. O primeiro número, publicado em dezembro de 1999 apresenta a organização e os programas por ela desenvolvidos. Neste primeiro número, a organização indica as áreas em que atua: "'pesquisa, com objetivo de aprofundar questões específicas da mulher: em especial da mulher negra, e subsidiar grupos que trabalhem com as questões de gênero e raça/ etnia"”.

Na apresentação, Maria Mulher indica os programas que realiza naquele momento. A organização desenvolve o projeto Construindo a Cidadania da Mulher Vítima de Violência Doméstica na Cruzeiro do Sul, vila popular de Porto Alegre, a fim de trabalhar a cidadania das mulheres empobrecidas que são ou foram vítimas de violência doméstica. "'A organização entende que a violência doméstica é um problema de saúde pública, apresentando custos para toda a sociedade e deve ser assumida pelo poder público"'.

Finalizando é apresentada a estruturação do atendimento realizado com as vítimas de violência doméstica:

... oficinas de auto-estima; oficinas de alfabetização; seminários em diversas áreas, relacionando sempre gênero, classe e raça/etnia; encaminhamentos jurídicos; encaminhamentos para atendimentos médicos da Rede Pública de Saúde e a serviços especializados no tratamento a mulheres vítimas de violência doméstica e a meninas e adolescentes vítimas de abuso sexual (Palavras de Maria Mulher, 1999).

O editorial reforça a necessidade de combater às violências étnico-racial, sexual e física sofrida pelas mulheres. Apresenta a definição apresentada pela OMS - Organização Mundial de Saúde sobre violência doméstica, como sendo "... ato cometido por familiares ou outras pessoas que vivem no mesmo domicílio", reconhecendo esta questão é "um problema de saúde pública, pois afeta a integridade física e a saúde mental da mulher".

Na conclusão do Editorial, a organização apresenta a finalidade com a qual o Boletim foi criado, sendo:

espaço de reflexão e divulgação do trabalho da organização no combate à violência contra a mulher e ao abuso sexual de meninas/adolescentes. O combate à violência contra a mulher requer uma luta diária. Exige o compromisso da sociedade para que haja a implantação de políticas públicas que efetivamente defenda e garantam os direitos das mulheres vitimadas (Palavras de Maria Mulher, 1999).

Ainda em Palavras de Maria Mulher são detalhados os objetivos traçados pela organização para o atendimento psicossocial a mulheres vítimas de violência doméstica. 
O objetivo do atendimento psicossocial é contribuir para a reestruturação emocional e social das mulheres vítimas de violência doméstica da Região Cruzeiro do Sul. A maioria das mulheres atendidas pela entidade carece de informações sobre saúde reprodutiva, direitos sexuais e reprodutivos... São mulheres empobrecidas, na sua quase totalidade, chefes de família que não possuem os direitos mínimos à cidadania assegurados.

O n. 2, publicado em dezembro de 2002 trouxe temas ligados à saúde mental das mulheres negras, informações sobre o Programa SOS Racismo e dados sobre a incidência do HIV/AIDS na população feminina e sua maior incidência nas mulheres negras.

O artigo sobre o tema HIV/AIDS informa que Maria Mulher executa vários projetos simultaneamente, a fim de informar as mulheres sobre seus direitos, realizando atividades que visam a sua estruturação emocional, além de incentivar a capacitação profissional. No projeto "Cuidar da Saúde é coisa de mulher" o objetivo principal é contribuir para a redução da incidência da transmissão de DST/HIV/AIDS. O projeto constatou que as mulheres têm pouca influência na negociação nos relacionamentos, sendo "obrigadas" a relacionarem-se sexualmente/praticarem o coito sem a utilização de preservativos, aumentando com isso o índice de contágio das doenças sexualmente transmissíveis, do vírus da Aids. O projeto tem por finalidade:

aumentar o acesso das pessoas atendidas aos serviços locais de saúde: que as mulheres portadoras do vírus HIV, com DST ou doentes de AIDS sejam capacitadas para exercerem atividades profissionais: que as pessoas atingidas pelo projeto demonstrem habilidade para o uso do preservativo e que relatem efetiva adesão ao tratamento anti-retroviral (Palavras de Maria Mulher, 2002).

Os dados levantados sobre a maneira de contágio indicam que $2 \%$ das mulheres foram contaminadas pelo uso de drogas e outros; $98 \%$ foram através do relacionamento conjugal/sexual. No que se refere à raça/etnia, $18 \%$ são brancas e $82 \%$ são mulheres negras. No que se refere à faixa etária o índice maior, cerca de $63 \%$ encontram-se na faixa dos 20 - 29 anos: $29 \%$ entre $30-39$ anos; $5 \%$ até 20 anos e $3 \%$ entre 40 e 49 anos.

O Programa SOS Racismo relata o seu histórico em artigo que refere a parceria que a Organização realizou com o Ministério da Justiça, a Secretaria dos Direitos Humanos e o Departamento de Promoção dos Direitos Humanos, em 2001, quando inicia o Programa. Relata que o mesmo oferece assessoramento jurídico e atendimento psicossocial para as vítimas de discriminação, a fim de que reajam e denunciem a violência sofrida.

Outra publicação é a Revista de Maria Mulher - Organização de Mulheres Negras, publicada em dezembro de 2002. Nesta publicação, aparece a descrição dos vários programas desenvolvidos pela organização. Além da explicitação sobre cada programa, são apresentadas fotografias das profissionais e de usuórias nas vórias atividades desenvolvidas.

\section{Conclusão}

Maria Mulher - Organização de Mulheres Negras, mais uma vez, ressalta a importância da existência de espaços para a publicação da produção textual das entidades de feministas negras, de mulheres negras e do movimento negro e popular, a fim de garantir a possibilidade de construção e divulgação de referenciais das lutas que realizam.

É importante ressaltar sempre que as organizações vêm dando conta de divulgar o trabalho realizado em suas entidades, de uma forma original, eficaz e eficiente, superando os obstáculos causados pela estrutura discriminadora e excludente que afasta do acesso às modernas tecnologias a uma parcela significativa da população brasileira.

Tendo em vista a dificuldade de encontrar patrocinadores para subsidiar a produção textual destas organizações, Maria Mulher propõe a realização de consórcios para a 
publicação de material produzido. A organização traz como exemplo a participação das organizações dos movimentos de mulheres negras na obra Experiências em Advocacy em Saúde e Direitos Sexuais e Reprodutivos, produzido pela AGENDE - Ações de Gênero, Cidadania e Desenvolvimento, em 2002, quando através de concurso, foram selecionadas nove entidades que tiveram seus textos publicados.

Neste momento, Maria Mulher sugere à Articulação de Mulheres Negras de ONGs que seja feita uma publicação envolvendo todas as suas entidades. Destinar-se-ia um determinado número de laudas para cada entidade, nas quais cada uma poderia tratar de um tema de sua vivência. Foi desta forma que a entidade apresentou nacionalmente o trabalho que realiza com mulheres vítimas de violência de gênero há cinco anos, na Vila Grande Cruzeiro em Porto Alegre.

A construção de revistas e jornais eletrônicos com temáticas compartilhadas é outra forma de divulgação da produção textual destas organizações, porém esbarra na baixa acessibilidade a esta forma de comunicação.

\section{Notas}

Copyright $\odot 2004$ by Revista Estudos Feministas.

' Sueli CARNEIRO e Thereza SANTOS, 1985.

\section{Referências}

AGENDE - Ações em Gênero, Cidadania e Desenvolvimento. Experiências em Advocacy em Saúde e Direitos Sexuais e Reprodutivos. Brasília, 2002.

BOLETIM de Maria Mulher. Ano 1, n. 1, Porto Alegre, nov. 1987.

BOLETIM de Maria Mulher. Ano 1, n. 2, Porto Alegre, jan. 1988.

BOLETIM MARIA MULHER. Palavras de Maria Mulher, n. 1, 1999.

BOLETIM Maria Mulher. Palavras de Maria Mulher- Organização de Mulheres Negras. Ano 2, n. 2, Porto Alegre, dezembro de 2002.

CARNEIRO, Sueli e SANTOS, Thereza. Mulher Negra. São Paulo:Nobel/Conselho Estadual da Condição Feminina, 1985.

MARIA MULHER - Organização de Mulheres Negras. "SOS Racismo: um serviço essencial para a cidadania". Passaporte para os Direitos Humanos 1. Porto Alegre, 2000.

MARIA MULHER - Organização de Mulheres Negras. "Previna-se da AIDS: proteja-se da violência". Passaporte para os Direitos Humanos, 2. Cuidar da Saúde é Coisa de Mulher. Porto Alegre, 2002.

REVISTA de Maria Mulher - Organização de Mulheres Negras. Porto Alegre, dezembro de 2002.

The Written Production of Black Women

Abstract: The paper presents an analysis of the articles published for Maria Mulher Organização de Mulheres Negras, in order of taking care of its institucional mission. Initially it is made a presentation of the form that the organization gives information for the women, in special, for the blacks, in order to combat the discriminations by sex, of race/ethnic and of social class, in the programs that develops. The text also makes reference to the lack of organizations that stimulates the intellectual production of entities black feminists. Finally, the work points to the production of workmanships in order to increase the number of publications from the black women organizations, in accordance with the vocation of each institution.

Keywords: papers, shared, publications, vocation, entities 